\title{
The factors that helped in the development of East Asian countries and the extent of their application in Arab countries
}

\author{
Author: Huda Ahmed Khelwai \\ Department of Economics, College of Political Science \& Economics, Korea \\ University, South Korea \\ Email: khhuda1980@outlook.com
}

\begin{abstract}
:
The world is witnessing great developments in various sectors; some countries have managed to change their course and rise from the setbacks and crises they are going through to achieve great success in the indicators of development and economic growth that has facilitated the entire world, such as the great development that East Asian countries have gone through. It was able to turn into the greatest developed country in a short period of time, as it did not exceed 25 years; This prompted many other countries to identify the factors that helped this development, so this study aimed to identify the strategies used in these countries to achieve this degree of development, and how to apply them in the Arab countries, as well as to identify the policies followed to achieve development, as well as the obstacles Which stand before Arab countries to take the experiences of East Asian countries and try to counter them; The descriptive approach was used to analyze all the data on the subject of the study, and described the most important stages that these countries went through to reach this development to come out with conclusions that can be applied in developing countries to get rid of backwardness and follow the same approach of East Asian countries to achieve comprehensive development.
\end{abstract}

Keywords: East Asian countries, the Arab countries, Indonesia, development, factors. 


\section{Introduction:}

There are contemporary realities in our world today, and contemporary fluctuations in economic roles. This has led to the necessity of researching this issue, especially after the emergence of economic blocs and groups that caused crises in developing countries. For example, I found some countries that were suffering from major economic problems, but their conditions quickly changed to become one of the most developed countries and were able to rise again to turn into the most powerful countries in their economy and an example for other countries to contribute to achieving development.

Among these countries is "East Asia", as these countries formed a great experience in the field of development during a short period of time that destroyed the entire world and pushed countries to try to adopt their approach to get rid of economic dependencies and resist the factors of underdevelopment, especially in the Arab countries.

East Asian countries have relied on the method of planning to achieve development, laying down comprehensive strategies to achieve development in all areas, rather than focusing on one area, with a focus on the basic sectors to achieve high economic growth rates, such as "Indonesia, Malaysia, South Korea.(...

\section{Research Questions:}

The objectives of the study are achieved by answering the questions related to the subject of the scientific study, by answering the main question of the study, which is "What are the factors that helped in the development of East Asian countries, and the extent of their application in our Arab countries?

Through this main question, many sub-questions must be answered in order to achieve the objectives of the study, which are as follows:

- What kind of development did East Asian countries reach and succeed in achieving?

- What are the development plans in place in those countries to gain progress? 
- What are the economic policies pursued in East Asian countries in general and Indonesia in particular?

- What are the factors that led to the success of the East Asian Association "ASEAN" in achieving economic strength?

-What is the extent of implementing the policy of East Asian countries in the Arab countries?

- What are the future prospects for East Asia، and how to apply them in the Arab countries?

- What are the factors behind the failure of Arab countries to achieve Arab interdependence?

\section{Research aims:}

- Identifying the most important factors that helped East Asian countries to radically move to a tremendous level of development.

- Identify the success factors of the Indonesian experience.

- Identify the strategy used in the economic system to promote it.

- Identify the most important factors that hinder the Arab countries in achieving this development.

- Learn about the economic growth aspects of the countries of Southeast Asia.

- Learn about the most important experiments that have been implemented in Arab countries، such as the experiences of East Asia.

- Identify the impact of applying development strategies affecting the development of East Asian countries.

\section{The importance of research:}

This scientific research is of utmost importance in both the practical and the scientific field, as it provides a model for economic development to contribute to its application in the Arab countries and works to change the reality of developing 
countries, and the ability to benefit from the experiences of other countries such as East Asian countries in general, and Indonesia in particular.

In addition, this topic represents contemporary importance in the field in order to get acquainted with the adopted policies and strategies that led to the achievement of development in countries, to clarify the factors of development and the achievement of development, and to confront the obstacles that stand in the way of achieving development in different countries. The subject of study also represents great importance in the field of research, the ability to conduct studies and research and start when others have finished, and the ability to come to new information and conclusions in the field of the subject of study.

\section{Research Methodology:}

This research uses the descriptive analytical method. As it conducts a comprehensive study of the reality of the topic and the phenomenon by collecting and analyzing data, informing and studying questions and trying to answer them in the subject of scientific research by accessing accurate information for all the elements of the research problem; This is to obtain important conclusions regarding the subject of research and their application in the scientific and practical field of the current subject of study.

\section{Research concepts:}

\section{In the convention:}

They are those processes that aim to bring about radical changes in a society to improve the level of individuals in it, through the exploitation of economic resources and their equitable distribution.

Procedural concept:

\section{Concept of evolution:}

These are the efforts exerted to coordinate between social and intellectual variables, in order to be able to increase production continuously, and to take into account the obstacles to achieving economic development and development. 
Economic development "economic development": are those processes that aim to achieve an orderly development in production, and take forms of precision by using very accurate techniques in the means used, taking into account the production conditions, and satisfying the needs of the individual and the group together, the definition of "Fouad Musa. "

It is a process that takes multi-dimensional forms, to bring about all changes in the social, economic, cultural, political and administrative levels, and to work to achieve economic growth in society, a fair distribution of national income among individuals and the elimination of poverty in society.

\section{Previous Studies:}

The first study: Ahmed Zahran, "Policies of Human Resources Management in the Civil Service in Malaysia and Indonesia," (2014): This study explored all factors of development in East Asian countries, especially Malaysia and Indonesia, through knowing the strategies used for managing human resources. In countries, and knowing the policies followed in the management of civil services and everything related to the organizational and administrative structure, reaching the insurance benefits provided in the two countries, and drawing lessons learned for the development of management policies and their application in developing countries, and the study used the descriptive approach to analyze the information reached by the results and link them to the topic of research.

The second study: Ali Awad Al-Sharaa: "ASEAN and the experience of regional cooperation" A study of the components of the experience, its challenges and the possibilities of benefiting from it 1997 AD: This study aimed to identify the impact of the global system on international relations and how some countries benefited and established ways of cooperation between them, and the elimination of the problems of clusters Economic matters such as East Asian countries and the alliance of countries with some, such as the experience of ASEAN, and the extent to which Arab countries benefit from this experience and identify the reasons for the inability of the Arab countries to achieve unity and integration between them, by answering the study questions, How is ASEAN to be ? 
What are its objectives and what are the challenges that The Arab countries faced in achieving integration? What are the experiences in achieving the integration of Arab countries within the framework of the ASEAN experience? The researcher used the analytical method in deducing facts and comparing both ASEAN and Arab countries in achieving unity.

The third study: Adel Beljebel: "Developmental Experiences of Emerging Economies in Southeast Asia and Their Possibility to Benefit in Algeria, $\mathrm{PhD}$ Thesis, 2016 AD.

This study aimed to highlight the aspects of development in East Asian countries, comprehensive development plans and radical reforms, and the success these countries achieved at the economic and social level, and the researcher tried to show the obstacles that these countries faced, and find out ways to solve them so that they can be applied in Arab countries, and the researcher used the descriptive approach. To get acquainted with the experiences that East Asian countries have gone through, and to contribute to finding the best ways to implement development plans in Arab countries

The factors that helped in the development of East Asian countries, "Indonesia As example":

The success of East Asian countries in achieving their development depends mainly on achieving economic development and making radical changes in society. Based on that, there are a set of main elements on which the development process has depended, namely:

- The principle of integration and inclusion: That is, the attempt of these countries to achieve radical changes in the economic, political and social aspects in order to achieve balance in all sectors.

- The ability to change productive structures: The countries of East Asia, especially Indonesia, are adopting a strategy to change the production structure in general, in order to achieve expansion in capacities and diversification of production at all levels, 
in order to be able to create markets for work and to achieve the principle of productive flexibility was one of the most important factors that helped the development of this economy Countries.

- Reliance on improving services provided to individuals: East Asian countries have benefited from the factors behind the developing countries 'underdevelopment of the economic level of the individual and worked to improve it, as well as interest in services and goods provided to individuals and the elimination of poor health conditions, housing, overcrowding, and attention to the poor classes in society. It led to the success of this experiment in a short time and the tremendous economic leap that was achieved by paying attention to these factors.

Attention to the principle of equitable distribution of the per capita share in society: to ensure the preservation of the poor classes; This is because of the belief of these countries that the principle of development and development can only be achieved by achieving justice in society.

\section{The ASEAN and Arab integration experience:}

The experience of ASEAN represents a unique model for Arab integration for countries that suffer from ethnic, religious, and ideological crises and differences, or between countries that suffer from wars and conflicts. That is, we find that the Arab countries have not succeeded in achieving Arab unity in a distinct manner despite the opportunities before them to achieve Arab integration, which is represented in (the unity of culture, religion and language). We may see that the Arab countries went through this experience before and preceded the ASEAN, so we find that in 1967, the year in which the "ASEAN" was established, the Arab League was established earlier this year in 1945 AD. At that time, the Arab countries were living under a regional system sponsored by The Arab League established committees for economic affairs, and the success of the Arab countries in establishing and establishing rules for economic cooperation between the various Arab countries. 
After that, the League Council issued decisions affirming the importance of cooperation between both national security and economic security through the 1950 AD treaty, and formulating this through projects and policies for cooperation between Arab countries.

Within the framework of implementing Arab integration, a council for joint defense was established, as well as a council that examines economic affairs, in cooperation with Arab ministers, to discuss all different economic issues.

Note: I found many obstacles to achieving Arab integration and its unity for Arab and international political reasons, and the implementation of these actual measures only began in 1964.

Weak Arab cooperation due to: The absence of agencies responsible for good planning and implementation.

The duplication of goals due to the large number of Arab organizations, which led to wasted efforts.

\section{Factors of weak Arab integration:}

Leadership: the absence of an idea of a good choice of leaders in Arab institutions. This led to the weakness of the institutional models in the economic direction, as well as the weakness of the supervisory committees. The situation was exploited to thwart the experience of integrating Arab unity.

Structural patterns: The basis of the integration process comes from the main structure of the economy. There were problems related to the developmental structure that was represented by foreign dependency.

Political will: The lack of information had an impact on political decision-makers. There is also a problem in this aspect, which is setting up immediate plans and not looking to the future.

The strategy of implementing the Arab countries to achieve integration and development, like East Asian countries:

1 (Emphasizing the importance of joint economic action among Arab countries. 
2 (Activating implementation mechanisms, not just planning, to achieve Arab unity.

3 (trying to separate politics and economics; And try to focus on achieving public interests.

4 (Paying attention to national security and working in groups in order to achieve the possibility of joint national security.

\section{Conclusion:}

This study attempted to address the most important factors that helped East Asian countries achieve this tremendous development at different levels, and found that they use a high strategy for economic growth, so it was found that planning for development by setting a strategy and starting implementation is one of the most important factors that helped implement their plans And its success in this, and the study indicated that there are some Arab countries that have taken the same approach as East Asian countries to achieve development, and other Arab countries see that the experience of East Asian countries is unique and difficult to apply in our Arab countries due to special circumstances that helped them achieve progress, and there are obstacles that stand before Arab countries Although the idea of Arab integration existed from before the ASEAN experience, it lacked good planning and implementation.

\section{Recommendations:}

The Arab countries attempt to overlook any political problems and disagreements that hinder development plans and achieve Arab and economic integration. The Arab League will settle these differences and try to find solutions to them.

Taking advantage of the factors that helped countries achieve their development, such as East Asian countries, and try to apply them in our Arab countries.

- Work to support means of cooperation between the two-dimensional and threedimensional Arab countries, and the need to adopt the principle of collective action in relations. 
- Paying attention to the economic conditions, encouraging investment in the Arab countries, and providing attractive factors.

\section{References:}

Ahmed Ibrahim Mahmoud: "Strategic Shifts and the Problematic Conflict and Security in Southeast Asia,” International Politics, 1994.

-Emad Gad: "Regional Integration in Asia, the ASEAN Experience," Center for Political and Strategic Studies, 1995.

Abdel-Fadil Mahmoud: "The Arabs and the Asian Experience, Lessons Learned", Center for Arab Unity Studies, Beirut, 2002 AD.

Omar Laaini: "Investment and its Impact on Economic Development", Master Thesis, College of Economics and Management Sciences, 2000 AD.

-Ramzi Ali Ibrahim Salama: "Development Economics", University House for Publishing and Distribution, Alexandria, 1991, p. 108.

-Moufid Shehab: “- Regional International Organizations”, Dar Al-Nahda A1Arabiya, Cairo, 1978 AD.

Saif Al-Din Abdel Fattah: "The Great Asian Political Ideas in the Twentieth Century," 2001 AD.

-Michel Twadro: "Economic Development," translated by: Mahmoud Hosni, Mahmoud Abdel-Razek, Marikh House for Publishing and Distribution, Riyadh, 2006.

-Majdi Abdullah, Fawaz Al-Hasawneh: "Structural Adjustment Policies and the Class of the National State, a comparative study of Malaysia and Indonesia during the period (1990: 2000), PhD thesis, Amman, 2002 AD.

Copyright (C 2021 Huda Ahmed Khelwai, AJRSP. This is an open-access article distributed under the terms of the Creative Commons Attribution License (CC BY NC). https://doi.org/10.52132/Ajrsp/en.2235 